\title{
FIXED POINT RESULTS FOR GENERALIZED RATIONAL $\alpha$-GERAGHTY CONTRACTION
}

\author{
MUHAMMAD ARSHAD AND AFTAB HUSSAIN
}

Received 15 October, 2014

\begin{abstract}
In this paper, an effort has been made to improve the notion of $\alpha$-Geraghty contraction type mappings and establish some common fixed point theorems for a pair of $\alpha$-admissible mappings under the improved approach of generalized rational $\alpha$-Geraghty contractive type condition in a complete metric space. An example has been constructed to demonstrate the novelty of these results.
\end{abstract}

2010 Mathematics Subject Classification: 46S40; 47H10; 54H25

Keywords: fixed point, contraction type mapping, rational $\alpha$-Geraghty contraction type mapping, triangular $\alpha$-admissible, metric space

\section{PRELIMINARIES AND SCOPE}

In 1973, Geraghty [3] studied a generalization of Banach contraction principle. He generalized the Banach contraction principle in a different way than it was done by different investigators. In 2012, Samet et al. [16], introduced a concept of $\alpha-\psi$ - contractive type mappings and established various fixed point theorems for mappings in complete metric spaces. Afterwards, Karapinar [11], refined the notion and obtained various fixed point results. See more results in [9]. Hussain et al. [7], generalized the concept of $\alpha$-admissible mappings and proved fixed point theorems. Subsequently, Abdeljawad [1] introduced a pair of $\alpha$-admissible mappings satisfying new sufficient contractive conditions different from those in [7], [16] and obtained fixed point and common fixed point theorems. Salimi et al. [15], modified the concept of $\alpha-\psi-$ contractive mappings and established fixed point results. Recently, Hussain et al. [8] proved some fixed point results for single and set-valued $\alpha-\eta-\psi$-contractive mappings in the setting of complete metric space. Mohammadi et al. [13], introduced a new notion of $\alpha-\phi$-contractive mappings and showed that it was a real generalization for some old results. Thereafter, many papers have published on geraghty contractions. For more detail see $[4-6,8,11,14]$ and references therein.

Definition 1 ([16]). Let $S: X \rightarrow X$ and $\alpha: X \times X \rightarrow \mathbb{R}$. We say that $S$ is $\alpha$ admissible if $x, y \in X, \alpha(x, y) \geq 1 \Rightarrow \alpha(S x, S y) \geq 1$. 
Example 1 ([12]). Consider $X=[0, \infty)$, and define $S: X \rightarrow X$ and $\alpha: X \times X \rightarrow$ $[0, \infty)$ by $S x=2 x$, for all $x, y \in X$ and

$$
\alpha(x, y)=\left\{\begin{aligned}
e^{\frac{y}{x}}, & \text { if } x \geq y, x \neq 0 \\
0, & \text { if } x<y .
\end{aligned}\right.
$$

Then $S$ is $\alpha$-admissible.

Definition 2 ([1]). Let $S, T: X \rightarrow X$ and $\alpha: X \times X \rightarrow[0,+\infty)$. We say that the pair $(S, T)$ is $\alpha$-admissible if $x, y \in X$ such that $\alpha(x, y) \geq 1$, then we have $\alpha(S x, T y) \geq 1$ and $\alpha(T x, S y) \geq 1$.

Definition 3 ([10]). Let $S: X \rightarrow X$ and $\alpha: X \times X \rightarrow[0,+\infty)$. We say that $S$ is triangular $\alpha$-admissible if $x, y \in X, \alpha(x, z) \geq 1$ and $\alpha(z, y) \geq 1 \Rightarrow \alpha(x, y) \geq 1$.

Definition 4 ([10]). Let $S: X \rightarrow X$ and $\alpha: X \times X \rightarrow(-\infty,+\infty)$. We say that $S$ is a triangular $\alpha$-admissible mapping if

(T1) $\alpha(x, y) \geq 1$ implies $\alpha(S x, S y) \geq 1, x, y \in X$,

(T2) $\alpha(x, z) \geq 1, \alpha(z, y) \geq 1$, implies $\alpha(x, y) \geq 1, x, y, z \in X$.

Definition 5 ([1]). Let $S, T: X \rightarrow X$ and $\alpha: X \times X \rightarrow(-\infty,+\infty)$. We say that a pair $(S, T)$ is triangular $\alpha$-admissible if

(T1) $\alpha(x, y) \geq 1$, implies $\alpha(S x, T y) \geq 1$ and $\alpha(T x, S y) \geq 1, x, y \in X$.

(T2) $\alpha(x, z) \geq 1, \alpha(z, y) \geq 1$, implies $\alpha(x, y) \geq 1, x, y, z \in X$.

Definition 6 ([15]). Let $S: X \rightarrow X$ and let $\alpha, \eta: X \times X \rightarrow[0,+\infty)$ be two functions. We say that $T$ is $\alpha$-admissible mapping with respect to $\eta$ if $x, y \in X$, $\alpha(x, y) \geq \eta(x, y) \Rightarrow \alpha(S x, S y) \geq \eta(S x, S y)$. Note that if we take $\eta(x, y)=1$, then this definition reduces to definition in [16]. Also if we take $\alpha(x, y)=1$, then we says that $S$ is an $\eta$-subadmissible mapping.

Lemma 1 ([2]). Let $S: X \rightarrow X$ be a triangular $\alpha$-admissible mapping. Assume that there exists $x_{0} \in X$ such that $\alpha\left(x_{0}, S x_{0}\right) \geq 1$. Define a sequence $\left\{x_{n}\right\}$ by $x_{n+1}=$ $S x_{n}$. Then we have $\alpha\left(x_{n}, x_{m}\right) \geq 1$ for all $m, n \in \mathbb{N} \cup\{0\}$ with $n<m$.

Lemma 2. Let $S, T: X \rightarrow X$ be a triangular $\alpha$-admissible mapping. Assume that there exists $x_{0} \in X$ such that $\alpha\left(x_{0}, S x_{0}\right) \geq 1$. Define sequence $x_{2 i+1}=S x_{2 i}$, and $x_{2 i+2}=T x_{2 i+1}$, where $i=0,1,2, \ldots$. Then we have $\alpha\left(x_{n}, x_{m}\right) \geq 1$ for all $m, n \in \mathbb{N} \cup\{0\}$ with $n<m$.

We denote by $\Omega$ the family of all functions $\beta:[0,+\infty) \rightarrow[0,1)$ such that, for any bounded sequence $\left\{t_{n}\right\}$ of positive reals, $\beta\left(t_{n}\right) \rightarrow 1$ implies $t_{n} \rightarrow 0$.

Theorem 1 ([3]). Let $(X, d)$ be a metric space. Let $S: X \rightarrow X$ be a self mapping. Suppose that there exists $\beta \in \Omega$ such that for all $x, y \in X$,

$$
d(S x, S y) \leq \beta(d(x, y)) d(x, y) .
$$

then $S$ has a fixed unique point $p \in X$ and $\left\{S^{n} x\right\}$ converges to $p$ for each $x \in X$. 


\section{Results}

In this section, we prove some fixed point theorems satisfying generalized rational $\alpha$-Geraghty contraction type mappings in complete metric space. Let $(X, d)$ be a metric space, and let $\alpha: X \times X \rightarrow \mathbb{R}$ be a function. Let $S, T: X \rightarrow X$ is called a pair of generalized rational $\alpha$-Geraghty contraction type mappings if there exists $\beta \in \Omega$ such that for all $x, y \in X$,

$$
\alpha(x, y) d(S x, T y) \leq \beta(M(x, y)) M(x, y)
$$

where

$$
M(x, y)=\max \left\{d(x, y), \frac{d(x, S x) d(y, T y)}{1+d(x, y)}, \frac{d(x, S x) d(y, T y)}{1+d(S x, T y)}\right\} .
$$

If $S=T$ then $T$ is called generalized rational $\alpha$-Geraghty contraction type mappings if there exists $\beta \in \Omega$ such that for all $x, y \in X$,

$$
\alpha(x, y) d(T x, T y) \leq \beta(N(x, y)) N(x, y)
$$

where

$$
N(x, y)=\max \left\{d(x, y), \frac{d(x, T x) d(y, T y)}{1+d(x, y)}, \frac{d(x, T x) d(y, T y)}{1+d(T x, T y)}\right\} .
$$

Theorem 2. Let $(X, d)$ be a complete metric space, $\alpha: X \times X \rightarrow \mathbb{R}$ be a function. Let $S, T: X \rightarrow X$ be two mappings then suppose that the following holds:

(i) $(S, T)$ is pair of generalized rational $\alpha$-Geraghty contraction type mapping;

(ii) $(S, T)$ is triangular $\alpha$-admissible;

(iii) there exists $x_{0} \in X$ such that $\alpha\left(x_{0}, S x_{0}\right) \geq 1$;

(iv) $S$ and $T$ are continuous;

Then $(S, T)$ have common fixed point.

Proof. Let $x_{1}$ in $X$ be such that $x_{1}=S x_{0}$ and $x_{2}=T x_{1}$. Continuing this process, we construct a sequence $x_{n}$ of points in $X$ such that,

$$
x_{2 i+1}=S x_{2 i} \text {, and } x_{2 i+2}=T x_{2 i+1} \text {, where } i=0,1,2, \ldots
$$

By assumption $\alpha\left(x_{0}, x_{1}\right) \geq 1$ and pair $(S, T)$ is $\alpha$-admissible, by Lemma 2, we have

$$
\alpha\left(x_{n}, x_{n+1}\right) \geq 1 \text { for all } n \in \mathbb{N} \cup\{0\} .
$$

Then

$$
\begin{aligned}
d\left(x_{2 i+1}, x_{2 i+2}\right) & =d\left(S x_{2 i}, T x_{2 i+1}\right) \leq \alpha\left(x_{2 i}, x_{2 i+1}\right) d\left(S x_{2 i}, T x_{2 i+1}\right) \\
& \leq \beta\left(M\left(x_{2 i}, x_{2 i+1}\right)\right) M\left(x_{2 i}, x_{2 i+1}\right),
\end{aligned}
$$

for all $i \in \mathbb{N} \cup\{0\}$. Now

$$
\begin{aligned}
M\left(x_{2 i}, x_{2 i+1}\right) & =\max \left\{d\left(x_{2 i}, x_{2 i+1}\right), \frac{d\left(x_{2 i}, S x_{2 i}\right) d\left(x_{2 i+1}, T x_{2 i+1}\right)}{1+d\left(x_{2 i}, x_{2 i+1}\right)}, \frac{d\left(x_{2 i}, S x_{2 i}\right) d\left(x_{2 i+1}, T x_{2 i+1}\right)}{1+d\left(S x_{2 i}, T x_{2 i+1}\right)}\right\} \\
& =\max \left\{d\left(x_{2 i}, x_{2 i+1}\right), \frac{d\left(x_{2 i}, x_{2 i+1}\right) d\left(x_{2 i+1}, x_{2 i+2}\right)}{1+d\left(x_{2 i}, x_{2 i+1}\right)}, \frac{d\left(x_{2 i}, x_{2 i+1}\right) d\left(x_{2 i+1}, x_{2 i+2}\right)}{1+d\left(x_{2 i+1}, x_{2 i+2}\right)}\right\}
\end{aligned}
$$


Thus

$$
\begin{aligned}
d\left(x_{2 i+1}, x_{2 i+2}\right) & \leq \beta\left(M\left(x_{2 i}, x_{2 i+1}\right)\right) M\left(x_{2 i}, x_{2 i+1}\right) \\
& \leq \beta\left(d\left(x_{2 i}, x_{2 i+1}\right)\right) d\left(\left(x_{2 i}, x_{2 i+1}\right)<d\left(x_{2 i}, x_{2 i+1}\right) .\right.
\end{aligned}
$$

so that,

$$
d\left(\left(x_{2 i+1}, x_{2 i+2}\right)<d\left(x_{2 i}, x_{2 i+1}\right) .\right.
$$

This implies that

$$
d\left(x_{n+1}, x_{n+2}\right)<d\left(x_{n}, x_{n+1}\right), \text { for all } n \in \mathbb{N} \cup\{0\} .
$$

So, sequence $\left\{d\left(x_{n}, x_{n+1}\right)\right\}$ is nonnegative and nonincreasing. Now, we prove that $d\left(x_{n}, x_{n+1}\right) \rightarrow 0$. It is clear that $\left\{d\left(x_{n}, x_{n+1}\right)\right\}$ is a decreasing sequence. Therefore, there exists some positive number $r$ such that $\lim _{n \rightarrow \infty} d\left(x_{n}, x_{n+1}\right)=r$. From $(2.4)$, we have

$$
\frac{d\left(x_{n+1}, x_{n+2}\right)}{d\left(x_{n}, x_{n+1}\right)} \leq \beta\left(d\left(x_{n}, x_{n+1}\right)\right) \leq 1 .
$$

Now by taking limit $n \rightarrow \infty$, we have

$$
1 \leq \beta\left(d\left(x_{n}, x_{n+1}\right)\right) \leq 1,
$$

that is

$$
\lim _{n \rightarrow \infty} \beta\left(d\left(x_{n}, x_{n+1}\right)\right)=1 .
$$

By the property of $\beta$, we have

$$
\lim _{n \rightarrow \infty} d\left(x_{n}, x_{n+1}\right)=0 .
$$

Now, we show that sequence $\left\{x_{n}\right\}$ is Cauchy sequence. Suppose on contrary that $\left\{x_{n}\right\}$ is not a Cauchy sequence. Then there exists $\epsilon>0$ and sequences $\left\{x_{m_{k}}\right\}$ and $\left\{x_{n_{k}}\right\}$ such that, for all positive integers $k$, we have $m_{k}>n_{k}>k$,

$$
d\left(x_{m_{k}}, x_{n_{k}}\right) \geq \epsilon
$$

and

$$
d\left(x_{m_{k}}, x_{n_{k-1}}\right)<\epsilon .
$$

By the triangle inequality, we have

$$
\begin{aligned}
\epsilon & \leq d\left(x_{m_{k}}, x_{n_{k}}\right) \\
& \leq d\left(x_{m_{k}}, x_{n_{k-1}}\right)+d\left(x_{n_{k-1}}, x_{n_{k}}\right) \\
& <\epsilon+d\left(x_{n_{k-1}}, x_{n_{k}}\right) .
\end{aligned}
$$

That is,

$$
\epsilon<\epsilon+d\left(x_{n_{k-1}}, x_{n_{k}}\right)
$$

for all $k \in \mathbb{N}$. In the view of (2.9), (2.6), we have

$$
\lim _{k \rightarrow \infty} d\left(x_{m_{k}}, x_{n_{k}}\right)=\epsilon .
$$


Again using triangle inequality, we have

$$
d\left(x_{m_{k}}, x_{n_{k}}\right) \leq d\left(x_{m_{k}}, x_{m_{k+1}}\right)+d\left(x_{m_{k+1}}, x_{n_{k+1}}\right)+d\left(x_{n_{k+1}}, x_{n_{k}}\right)
$$

and

$$
d\left(x_{m_{k+1}}, x_{n_{k+1}}\right) \leq d\left(x_{m_{k+1}}, x_{m_{k}}\right)+d\left(x_{m_{k}}, x_{n_{k}}\right)+d\left(x_{n_{k}}, x_{n_{k+1}}\right) .
$$

Taking limit as $k \rightarrow+\infty$ and using (2.6) and (2.10), we obtain

$$
\lim _{k \rightarrow+\infty} d\left(x_{m_{k+1}}, x_{n_{k+1}}\right)=\epsilon .
$$

By Lemma 2, $\alpha\left(x_{n_{k}}, x_{m_{k+1}}\right) \geq 1$, we have

$$
\begin{aligned}
d\left(x_{n_{k+1}}, x_{m_{k+2}}\right) & =d\left(S x_{n_{k}}, T x_{m_{k+1}}\right) \leq \alpha\left(x_{n_{k}}, x_{m_{k+1}}\right) d\left(S x_{n_{k}}, T x_{m_{k+1}}\right) \\
& \leq \beta\left(M\left(x_{n_{k}}, x_{m_{k+1}}\right)\right) M\left(x_{n_{k}}, x_{m_{k+1}}\right) .
\end{aligned}
$$

Finally, we conclude that

$$
\frac{d\left(x_{n_{k+1}}, x_{m_{k+2}}\right)}{M\left(x_{n_{k}}, x_{m_{k+1}}\right)} \leq \beta\left(M\left(x_{n_{k}}, x_{m_{k+1}}\right)\right) .
$$

By using (2.6), taking limit as $k \rightarrow+\infty$ in the above inequality, we obtain

$$
\lim _{k \rightarrow \infty} \beta\left(d\left(x_{n_{k}}, x_{m_{k+1}}\right)\right)=1 .
$$

So, $\lim _{k \rightarrow \infty} d\left(x_{n_{k}}, x_{m_{k+1}}\right)=0<\epsilon$, which is a contradiction. Hence $\left\{x_{n}\right\}$ is a Cauchy sequence. Since $X$ is complete so there exists $p \in X$ such that $x_{n} \rightarrow p$ implies that $x_{2 i+1} \rightarrow p$ and $x_{2 i+2} \rightarrow p$. As $S$ and $T$ are continuous, so we get $T x_{2 i+1} \rightarrow T p$ and $S x_{2 i+2} \rightarrow S p$. Thus $p=S p$ similarly, $p=T p$, we have $S p=T p=p$. Then $(S, T)$ have common fixed point.

In the following Theorem, we dropped continuity.

Theorem 3. Let $(X, d)$ be a complete metric space, $\alpha: X \times X \rightarrow \mathbb{R}$ be a function. Let $S, T: X \rightarrow X$ be two mappings then suppose that the following holds:

(i) $(S, T)$ is a pair of generalized rational $\alpha$-Geraghty contraction type mapping;

(ii) $(S, T)$ is triangular $\alpha$-admissible;

(iii) there exists $x_{0} \in X$ such that $\alpha\left(x_{0}, S x_{0}\right) \geq 1$;

(iv) if $\left\{x_{n}\right\}$ is a sequence in $X$ such that $\alpha\left(x_{n}, x_{n+1}\right) \geq 1$ for all $n \in \mathbb{N} \cup\{0\}$ and $x_{n} \rightarrow p \in X$ as $n \rightarrow+\infty$, then there exists a subsequence $\left\{x_{n_{k}}\right\}$ of $\left\{x_{n}\right\}$ such that $\alpha\left(x_{n_{k}}, p\right) \geq 1$ for all $k$.

Then $(S, T)$ have common fixed point.

Proof. Follows the similar lines of the Theorem 2. Define a sequence $x_{2 i+1}=$ $S x_{2 i}$, and $x_{2 i+2}=T x_{2 i+1}$, where $i=0,1,2, \ldots$ converges to $p \in X$. By the hypotheses of (iv) there exists a subsequence $\left\{x_{n_{k}}\right\}$ of $\left\{x_{n}\right\}$ such that $\alpha\left(x_{2 n_{k}}, p\right) \geq 1$ for all $k$. Now by using (2.1) for all $k$, we have

$$
d\left(x_{2 n_{k}+1}, T p\right)=d\left(S x_{2 n_{k}}, T p\right) \leq \alpha\left(x_{2 n_{k}}, p\right) d\left(S x_{2 n_{k}}, T p\right)
$$




$$
\leq \beta\left(M\left(x_{2 n_{k}}, p\right)\right) M\left(x_{2 n_{k}}, p\right) .
$$

so that,

$$
d\left(x_{2 n_{k}+1}, T p\right) \leq \beta\left(M\left(x_{2 n_{k}}, p\right)\right) M\left(x_{2 n_{k}}, p\right) .
$$

On the other hand, we obtain

$$
M\left(x_{2 n_{k}}, p\right)=\max \left\{d\left(x_{2 n_{k}}, p\right), \frac{d\left(x_{2 n_{k}}, S x_{2 n_{k}}\right), d(p, T p)}{1+d\left(x_{2 n_{k}}, p\right)}, \frac{d\left(x_{2 n_{k}}, S x_{2 n_{k}}\right), d(p, T p)}{1+d\left(S x_{2 n_{k}}, T p\right)}\right\} .
$$

Letting $k \rightarrow \infty$ then we have

$$
\lim _{k \rightarrow \infty} M\left(x_{2 n_{k}}, p\right)=\max \{d(p, S p), d(p, T p)\} .
$$

Case I.

$\lim _{k \rightarrow \infty} M\left(x_{2 n_{k}}, p\right)=d(p, T p)$. Suppose that $d(p, T p)>0$. From (2.14), for a large $k$, we have $M\left(x_{2 n_{k}}, p\right)>0$, which implies that

$$
\beta\left(M\left(x_{2 n_{k}}, p\right)\right)<M\left(x_{2 n_{k}}, p\right) .
$$

Then, we have

$$
d\left(x_{2 n_{k}}, T p\right)<M\left(x_{2 n_{k}}, p\right)
$$

Letting $k \rightarrow \infty$ in (2.15), we obtain that $d(p, T p)<d(p, T p)$, which is a contradiction. Thus, we find that $d(p, T p)=0$, implies $p=T p$.

Case II.

$\lim _{k \rightarrow \infty} M\left(x_{2 n_{k}}, p\right)=d(p, S p)$. Similarly $p=S p$. Thus $p=T p=S p$.

If $M(x, y)=\max \left\{d(x, y), \frac{d(x, S x) d(y, S y)}{1+d(x, y)}, \frac{d(x, S x) d(y, S y)}{1+d(S x, S y)}\right\}$ and $S=T$ in Theorem 2 and Theorem 3 , we have the following corollaries.

Corollary 1. Let $(X, d)$ be a complete metric space and let $S$ is $\alpha$-admissible mappings such that the following holds:

(i) $S$ is a generalized rational $\alpha$-Geraghty contraction type mapping;

(ii) $S$ is triangular $\alpha$-admissible;

(iii) there exists $x_{0} \in X$ such that $\alpha\left(x_{0}, T\left(x_{0}\right)\right) \geq 1$;

(iv) $S$ is continuous;

Then $S$ has a fixed point $p \in X$, and $S$ is a Picard operator, that is, $\left\{S^{n} x_{0}\right\}$ converges to $p$.

Corollary 2. Let $(X, d)$ be a complete metric space and let $S$ is $\alpha$-admissible mappings such that the following holds:

(i) $S$ is a generalized rational $\alpha$-Geraghty contraction type mapping;

(ii) $S$ is triangular $\alpha$-admissible;

(iii) there exists $x_{0} \in X$ such that $\alpha\left(x_{0}, S x_{0}\right) \geq 1$;

(iv) if $\left\{x_{n}\right\}$ is a sequence in $X$ such that $\alpha\left(x_{n}, x_{n+1}\right) \geq 1$ for all $n \in \mathbb{N} \cup\{0\}$ and $x_{n} \rightarrow p \in X$ as $n \rightarrow+\infty$, then there exists a subsequence $\left\{x_{n_{k}}\right\}$ of $\left\{x_{n}\right\}$ such that $\alpha\left(x_{n_{k}}, p\right) \geq 1$ for all $k$. 
Then $S$ has a fixed point $p \in X$, and $S$ is a Picard operator, that is, $\left\{S^{n} x_{0}\right\}$ converges to $p$.

If $M(x, y)=\max \{d(x, y), d(x, S x), d(y, S y)\}$ in Theorem 1, Theorem 2, we obtain the following corollaries.

Corollary 3 ([2]). Let $(X, d)$ be a complete metric space, $\alpha: X \times X \rightarrow \mathbb{R}$ be a function. Let $S: X \rightarrow X$ be a mapping then suppose that the following holds:

(i) $S$ is a generalized $\alpha$-Geraghty contraction type mapping;

(ii) $S$ is triangular $\alpha$-admissible;

(iii) there exists $x_{0} \in X$ such that $\alpha\left(x_{0}, S x_{0}\right) \geq 1$;

(iv) $S$ is continuous;

Then $S$ has a fixed point $p \in X$, and $S$ is a Picard operator, that is, $\left\{S^{n} x_{0}\right\}$ converges to $p$.

Corollary 4 ([2]). Let $(X, d)$ be a complete metric space, $\alpha: X \times X \rightarrow \mathbb{R}$ be a function. Let $S: X \rightarrow X$ be a mapping then suppose that the following holds:

(i) $S$ is a generalized $\alpha$-Geraghty contraction type mapping;

(ii) $S$ is triangular $\alpha$-admissible;

(iii) there exists $x_{0} \in X$ such that $\alpha\left(x_{0}, S x_{0}\right) \geq 1$;

(iv) if $\left\{x_{n}\right\}$ is a sequence in $X$ such that $\alpha\left(x_{n}, x_{n+1}\right) \geq 1$ for all $n \in \mathbb{N} \cup\{0\}$ and $x_{n} \rightarrow p \in X$ as $n \rightarrow+\infty$, then there exists a subsequence $\left\{x_{n_{k}}\right\}$ of $\left\{x_{n}\right\}$ such that $\alpha\left(x_{n_{k}}, p\right) \geq 1$ for all $k$.

Then $S$ has a fixed point $p \in X$, and $S$ is a Picard operator, that is, $\left\{S^{n} x_{0}\right\}$ converges to $p$.

Let $(X, d)$ be a metric space, and let $\alpha, \eta: X \times X \rightarrow \mathbb{R}$ be a function. A map $S, T: X \rightarrow X$ is called a pair of generalized rational $\alpha$-Geraghty contraction type mappings if there exists $\beta \in \Omega$ such that for all $x, y \in X$,

$$
\alpha(x, y) \geq \eta(x, y) \Rightarrow d(S x, T y) \leq \beta(M(x, y)) M(x, y)
$$

where

$$
M(x, y)=\max \left\{d(x, y), \frac{d(x, S x) d(y, T y)}{1+d(x, y)}, \frac{d(x, S x) d(y, T y)}{1+d(S x, T y)}\right\} .
$$

Theorem 4. Let $(X, d)$ be a complete metric space. Let $S$ is $\alpha$-admissible mappings with respect to $\eta$ such that the following holds:

(i) $(S, T)$ is a generalized rational $\alpha$-Geraghty contraction type mapping;

(ii) $(S, T)$ is triangular $\alpha$-admissible;

(iii) there exists $x_{0} \in X$ such that $\alpha\left(x_{0}, S x_{0}\right) \geq \eta\left(x_{0}, S x_{0}\right)$;

(iv) $S$ and $T$ are continuous;

Then $(S, T)$ have common fixed point. 
Proof. Let $x_{1}$ in $X$ be such that $x_{1}=S x_{0}$ and $x_{2}=T x_{1}$. Continuing this process, we construct a sequence $x_{n}$ of points in $X$ such that,

$$
x_{2 i+1}=S x_{2 i}, \text { and } x_{2 i+2}=T x_{2 i+1}, \text { where } i=0,1,2, \ldots
$$

By assumption $\alpha\left(x_{0}, x_{1}\right) \geq \eta\left(x_{0}, x_{1}\right)$ and the pair $(S, T)$ is $\alpha$-admissible with respect to $\eta$, we have, $\alpha\left(S x_{0}, T x_{1}\right) \geq \eta\left(S x_{0}, T x_{1}\right)$ from which we deduce that $\alpha\left(x_{1}, x_{2}\right) \geq$ $\eta\left(x_{1}, x_{2}\right)$ which also implies that $\alpha\left(T x_{1}, S x_{2}\right) \geq \eta\left(T x_{1}, S x_{2}\right)$. Continuing in this way we obtain $\alpha\left(x_{n}, x_{n+1}\right) \geq \eta\left(x_{n}, x_{n+1}\right)$ for all $n \in \mathbb{N} \cup\{0\}$.

$$
\begin{aligned}
d\left(x_{2 i+1}, x_{2 i+2}\right) & =d\left(S x_{2 i}, T x_{2 i+1}\right) \leq \alpha\left(x_{2 i}, x_{2 i+1}\right) d\left(S x_{2 i}, T x_{2 i+1}\right) \\
& \leq \beta\left(M\left(x_{2 i}, x_{2 i+1}\right)\right) M\left(x_{2 i}, x_{2 i+1}\right),
\end{aligned}
$$

Therefore,

for all $i \in \mathbb{N} \cup\{0\}$. Now

$$
d\left(x_{2 i+1}, x_{2 i+2}\right) \leq \alpha\left(x_{2 i}, x_{2 i+1}\right) d\left(S x_{2 i}, T x_{2 i+1}\right)
$$

$$
\begin{aligned}
M\left(x_{2 i}, x_{2 i+1}\right) & =\max \left\{d\left(x_{2 i}, x_{2 i+1}\right), \frac{d\left(x_{2 i}, S x_{2 i}\right) d\left(x_{2 i+1}, T x_{2 i+1}\right)}{1+d\left(x_{2 i}, x_{2 i+1}\right)}, \frac{d\left(x_{2 i}, S x_{2 i}\right) d\left(x_{2 i+1}, T x_{2 i+1}\right)}{1+d\left(S x_{2 i}, T x_{2 i+1}\right)}\right\} \\
& =\max \left\{d\left(x_{2 i}, x_{2 i+1}\right), \frac{d\left(x_{2 i}, x_{2 i+1}\right) d\left(x_{2 i+1}, x_{2 i+2}\right)}{1+d\left(x_{2 i}, x_{2 i+1}\right)}, \frac{d\left(x_{2 i}, S x_{2 i}\right) d\left(x_{2 i+1}, T x_{2 i+1}\right)}{1+d\left(x_{2 i+1}, x_{2 i+2}\right)}\right\} \\
& \leq \max \left\{d\left(x_{2 i}, x_{2 i+1}\right), d\left(x_{2 i+1}, x_{2 i+2}\right)\right\} .
\end{aligned}
$$

From the definition of $\beta$, the case $M\left(x_{2 i}, x_{2 i+1}\right)=d\left(x_{2 i+1}, x_{2 i+2}\right)$ is impossible.

$$
\begin{aligned}
d\left(x_{2 i+1}, x_{2 i+2}\right) & \leq \beta\left(M\left(x_{2 i}, x_{2 i+1}\right)\right) M\left(x_{2 i}, x_{2 i+1}\right) \\
& \leq \beta\left(d\left(x_{2 i+1}, x_{2 i+2}\right)\right) d\left(x_{2 i+1}, x_{2 i+2}\right)<d\left(x_{2 i+1}, x_{2 i+2}\right) .
\end{aligned}
$$

Which is a contradiction. Otherwise, in other case

$$
\begin{aligned}
d\left(x_{2 i+1}, x_{2 i+2}\right) & \leq \beta\left(M\left(x_{2 i}, x_{2 i+1}\right)\right) M\left(x_{2 i}, x_{2 i+1}\right) \\
& \leq \beta\left(d\left(x_{2 i}, x_{2 i+1}\right)\right) d\left(\left(x_{2 i}, x_{2 i+1}\right)<d\left(x_{2 i}, x_{2 i+1}\right) .\right.
\end{aligned}
$$

This, implies that

$$
d\left(x_{n+1}, x_{n+2}\right)<d\left(x_{n}, x_{n+1}\right), \text { for all } n \in \mathbb{N} \cup\{0\} .
$$

Follows the similar lines of the Theorem 2. Hence $p$ is common fixed point of $S$ and $T$.

Theorem 5. Let $(X, d)$ be a complete metric space and let $(S, T)$ are $\alpha$-admissible mappings with respect to $\eta$ such that the following holds:

(i) $(S, T)$ is a generalized rational $\alpha$-Geraghty contraction type mapping;

(ii) $(S, T)$ is triangular $\alpha$-admissible;

(iii) there exists $x_{0} \in X$ such that $\alpha\left(x_{0}, S x_{0}\right) \geq \eta\left(x_{0}, S x_{0}\right)$;

(iv) if $\left\{x_{n}\right\}$ is a sequence in $X$ such that $\alpha\left(x_{n}, x_{n+1}\right) \geq \eta\left(x_{n}, x_{n+1}\right)$ for all $n \in$ $\mathbb{N} \cup\{0\}$ and $x_{n} \rightarrow p \in X$ as $n \rightarrow+\infty$, then there exists a subsequence $\left\{x_{n_{k}}\right\}$ of $\left\{x_{n}\right\}$ such that $\alpha\left(x_{n_{k}}, p\right) \geq \eta\left(x_{n_{k}}, p\right)$ for all $k$.

Then $S$ and $T$ has common fixed point. 
Proof. Follows the similar line of the Theorem 3.

If $M(x, y)=\max \left\{d(x, y), \frac{d(x, S x) d(y, S y)}{1+d(x, y)}, \frac{d(x, S x) d(y, S y)}{1+d(S x, S y)}\right\}$ and $S=T$ in the Theorem 4, Theorem 5 , we get the following corollaries.

Corollary 5. Let $(X, d)$ be a complete metric space and let $S$ is $\alpha$-admissible mappings with respect to $\eta$ such that the following holds:

(i) $S$ is a generalized rational $\alpha$-Geraghty contraction type mapping;

(ii) $S$ is triangular $\alpha$-admissible;

(iii) there exists $x_{0} \in X$ such that $\alpha\left(x_{0}, S x_{0}\right) \geq \eta\left(x_{0}, S x_{0}\right)$;

(iv) $S$ is continuous;

Then $S$ has a fixed point $p \in X$, and $S$ is a Picard operator, that is, $\left\{S^{n} x_{0}\right\}$ converges to $p$.

Corollary 6. Let $(X, d)$ be a complete metric space and let $S$ is $\alpha$-admissible mappings with respect to $\eta$ such that the following holds:

(i) $S$ is a generalized rational $\alpha$-Geraghty contraction type mapping;

(ii) $S$ is triangular $\alpha$-admissible;

(iii) there exists $x_{0} \in X$ such that $\alpha\left(x_{0}, S x_{0}\right) \geq \eta\left(x_{0}, S x_{0}\right)$;

(iv) if $\left\{x_{n}\right\}$ is a sequence in $X$ such that $\alpha\left(x_{n}, x_{n+1}\right) \geq \eta\left(x_{n}, x_{n+1}\right)$ for all $n \in$ $\mathbb{N} \cup\{0\}$ and $x_{n} \rightarrow p \in X$ as $n \rightarrow+\infty$, then there exists a subsequence $\left\{x_{n_{k}}\right\}$ of $\left\{x_{n}\right\}$ such that $\alpha\left(x_{n_{k}}, p\right) \geq \eta\left(x_{n_{k}}, p\right)$ for all $k$.

Then $S$ has a fixed point $p \in X$, and $S$ is a Picard operator, that is, $\left\{S^{n} x_{0}\right\}$ converges to $p$.

Example 2. Let $X=\{1,2,3\}$ with metric

$$
\begin{aligned}
d(1,3) & =d(3,1)=\frac{5}{7} d(1,1)=d(2,2)=d(3,3)=0 \\
d(1,2) & =d(2,1)=1, d(2,3)=d(3,2)=\frac{4}{7} \\
\alpha(x, y) & =\left\{\begin{array}{ll}
1, & \text { if } x, y \in X, \\
0, & \text { otherwise }
\end{array}\right\} .
\end{aligned}
$$

Define the mappings $S, T: X \rightarrow X$ as follows:

$$
\begin{aligned}
S x & =1 \text { for each } x \in X . \\
T(1) & =T(3)=1, T(2)=3 .
\end{aligned}
$$

and $\beta:[0,+\infty) \rightarrow[0,1]$, then

$$
\alpha(x, y) d(T x, T y) \leq \beta(M(x, y)) M(x, y) .
$$

Let $x=2$ and $y=3$ then condition (2.1) is not satisfied.

$$
d(T(2), T(3))=d(3,1)=\frac{5}{7}
$$




$$
\begin{aligned}
M(x, y) & =\max \{d(2,3), d(2, T(2)), d(3, T(3))\} \\
& =\max \left\{\frac{4}{7}, \frac{4}{7}, \frac{5}{7}\right\}=\frac{5}{7}
\end{aligned}
$$

and

$$
\alpha(2,3) d(T(2), T(3)) \not \leq \beta(M(x, y)) M(x, y) .
$$

If

$$
\begin{aligned}
M(x, y) & =\max \left\{d(2,3), \frac{d(2, T(2)) d(3, T(3))}{1+d(2,3)}, \frac{d(2, T(2)) d(3, T(3))}{1+d(T 2, T 3)}\right\} \\
& =\max \left\{\frac{4}{7}, \frac{20}{77}, \frac{20}{84}\right\}=\frac{4}{7}
\end{aligned}
$$

Then the contractions does not holds.

$$
\alpha(2,3) d(T(2), T(3)) \not \leq \beta(M(x, y)) M(x, y) .
$$

We prove that Theorem 1 can be applied to $S$ and $T$. Let $x, y \in X$, clearly $(S, T)$ is $\alpha$-admissible mapping such that $\alpha(x, y) \geq 1$. Let $x, y \in X$ and so that $S x, T y \in X$ and $\alpha(S x, T y)=1$. Hence $(S, T)$ is $\alpha$-admissible. We show that condition (2.1) of Theorem 1 is satisfied. If $x, y \in X$ then $\alpha(x, y)=1$, we have

$$
\alpha(x, y) d(S x, T y) \leq \beta(M(x, y))(M(x, y)) .
$$

where

$$
\begin{aligned}
M(x, y) & =\max \left\{d(2,3), \frac{d(2, S(2)) d(3, T(3))}{1+d(2,3)}, \frac{d(2, S(2)) d(3, T(3))}{1+d(S 2, T 3)}\right\} \\
& =\max \left\{\frac{4}{7}, \frac{20}{77}, \frac{20}{49}\right\}=\frac{4}{7}
\end{aligned}
$$

and

$$
\begin{gathered}
d(S 2, T 3)=d(1,1)=0 . \\
\alpha(x, y) d(S x, T y) \leq \beta(M(x, y))(M(x, y)) .
\end{gathered}
$$

Hence all the hypothesis of the Theorem 1 is satisfied, So $S, T$ have a common fixed point.

Remark 1. More detail, applications and examples see in [2] and references there in. Our results are more general than those in [2], [15] and improve several results existing in the literature.

\section{ACKNOWLEDGEMENT}

The authors sincerely thank the learned referee for a careful reading and thoughtful comments. The present version of the paper owes much to the precise and kind remarks of anonymous referees. 


\section{REFERENCES}

[1] T. Abdeljawad, "Meir-keeler alpha-contractive fixed and common fixed point theorems," Fixed Point Theory and Applications, vol. 2013, no. 1, pp. 1-10, 2013.

[2] S.-H. Cho and J.-S. Bae, "Fixed point theorems for $\alpha$ - $\psi$-quasi contractive mappings in metric spaces," Fixed Point Theory and Applications, vol. 2013, no. 1, pp. 1-12, 2013.

[3] M. A. Geraghty, "On contractive mappings," Proceedings of the American Mathematical Society, vol. 40, no. 2, pp. 604-608, 1973.

[4] R. Haghi, S. Rezapour, and N. Shahzad, "Some fixed point generalizations are not real generalizations," Nonlinear Analysis: Theory, Methods \& Applications, vol. 74, no. 5, pp. 1799-1803, 2011.

[5] N. Hussain, P. Salimi, and P. Vetro, "Fixed points for $\alpha-\psi$-suzuki contractions with applications to integral equations," CARPATHIAN JOURNAL OF MATHEMATICS, vol. 30, no. 2, pp. 197-207, 2014.

[6] N. Hussain, M. Arshad, A. Shoaib et al., "Common fixed point results for $\alpha-\psi$-contractions on a metric space endowed with graph,” Journal of Inequalities and Applications, vol. 2014, no. 1, pp. $1-14,2014$.

[7] N. Hussain, E. Karapınar, P. Salimi, and F. Akbar, " $\alpha$-admissible mappings and related fixed point theorems," Journal of Inequalities and Applications, vol. 2013, no. 1, pp. 1-11, 2013.

[8] N. Hussain, P. Salimi, and A. Latif, "Fixed point results for single and set-valued $\alpha-\eta-\psi$ contractive mappings," Fixed Point Theory and Applications, vol. 2013, no. 1, pp. 1-23, 2013.

[9] E. Karapınar, "A discussion on" $\alpha-\psi$-geraghty contraction type mappings"," Filomat, vol. 28, no. 4, pp. 761-766, 2014.

[10] E. Karapınar, P. Kumam, and P. Salimi, “On $\alpha-\psi$-meir-keeler contractive mappings," Fixed Point Theory and Applications, vol. 2013, no. 1, pp. 1-12, 2013.

[11] E. Karapinar and B. Samet, "Generalized alpha-psi contractive type mappings and related fixed point theorems with applications," vol. 2012. Hindawi Publishing Corporation, 2012.

[12] M. A. Kutbi, M. Arshad, and A. Hussain, "On modified-contractive mappings," vol. 2014. Hindawi Publishing Corporation, 2014.

[13] B. Mohammadi and S. Rezapour, "On modified [alpha]-[[phi]-contractions," Journal of Advanced Mathematical Studies, vol. 6, no. 2, pp. 162-163, 2013

[14] B. E. Rhoades, "A comparison of various definitions of contractive mappings," Transactions of the American Mathematical Society, vol. 226, pp. 257-290, 1977.

[15] P. Salimi, A. Latif, and N. Hussain, "Modified $\alpha-\psi$-contractive mappings with applications," Fixed Point Theory and Applications, vol. 2013, no. 1, pp. 1-19, 2013.

[16] B. Samet, C. Vetro, and P. Vetro, "Fixed point theorems for $\alpha-\psi$-contractive type mappings," Nonlinear Analysis: Theory, Methods \& Applications, vol. 75, no. 4, pp. 2154-2165, 2012.

Authors' addresses

Muhammad Arshad

International Islamic University, Department of Mathematics and Statistics, H-10, Islamabad, Pakistan

E-mail address: marshadzia@iiu.edu.pk

\section{Aftab Hussain}

International Islamic University, Department of Mathematics and Statistics, H-10, Islamabad, Pakistan Current address: Khwaja Fareed University of Engineering \& Information Technology, 64200,

Rahim Yar Khan, Pakistan

E-mail address: aftabshegmail.com 